\title{
APONTAMENTOS ACERCA DO ESTADO DE EXCEÇÃO EM WALTER BENJAMIN
}

Elielvir Marinho do Nascimento

\begin{abstract}
RESUMO
Trata-se, no presente artigo, de apresentar o conceito benjaminiano de estado de exceção como um desdobramento da sua crítica da violência. Em debate com o jurista alemão Carl Schmitt, Benjamin apresenta uma crítica da Gewalt e afirma a existência de uma função "pura", "revolucionária" e, portanto, extrajurídica da violência capaz de estabelecer uma nova ordem jurídica e social que se configura, de acordo com a oitava das teses, como o "verdadeiro estado de exceção".
\end{abstract}

Palavras-Chave: Walter Benjamin. Carl Schmitt. Estado de Exceção. Gewalt. Fascismo.

\section{NOTES ABOUT THE STATE OF EXCEPTION IN WALTER BENJAMIN}

\begin{abstract}
This consists in this article to present the benjamin's concept state of exception as an offshoot of criticism of violence. In discussion with the german jurist Carl Schmitt, Benjamin presents a critique of Gewalt and affirms an function "pure", "revolutionary" and, therefore, extralegal of violence capable, according to the eighth of the theses, of stabelishing a new legal and social order which constitutes the "true state of exception".
\end{abstract}

Key-Words: Walter Benjamin. Carl Schmitt.State of Exception. Gewalt.Fascism. 


\section{Introdução}

A conjuntura social e política dos primeiros anos do século XXI revelam uma miríade de questões tão desconcertantes quanto cruciais para nós, habitantes do mundo contemporâneo. Herdeiro direto da configuração de poderes instituída nos primeiros anos que se seguiram à Segunda Grande Guerra Mundial, o cenário histórico atual suscita e exige daqueles que buscam compreendê-lo duas posturas teóricas básicas: primeiro, um distanciamento das "grandes narrativas" que caracterizam o projeto filosófico-cultural da modernidade com seus ideais genéricos e universalizantes; segundo, a coragem e a acuidade intelectual de experienciar o pensamento no âmbito da singularidade, do fragmento, portanto, "a contrapelo" dos discursos da história e do pensamento oficiais.

É no sentido de debater uma perspectiva de compreensão de alguns fenômenos que constituem o contemporâneo, que nos inspiramos para a escritura deste texto. Nele buscar-se-á apresentar, através da exposição do debate entre Walter Benjamin e Carl Schmitt, o conceito benjaminiano de "estado de exceção" como uma chave para a compreensão dos processos políticos que ocorrem atualmente no Brasil e no mundo.

A partir da leitura de alguns textos do filósofo Walter Benjamin, precisamente de Sobre a Crítica do Poder como Violência (1921) e das Teses sobre o Conceito de História (1940), teceremos uma reflexão acerca de como a violência legitimada pelo Direito e pelo Estado se configura como um dispositivo de manutenção da ordem social vigente.

Tal reflexão implica, portanto, no entendimento de como o aparato jurídico das democracias modernas instaura um novo tipo de governabilidade que implementa um paradigma de governo anunciado por Benjamin em sua oitava tese sobre o conceito de história: o movimento que leva o estado de exceção a tornar-se regra.

Por meio do debate com o jurista alemão Carl Schmitt, autor de, dentre outras obras, "Teologia Política" (Politische Theologie), buscaremos demonstrar como Walter Benjamin constrói o seu pensamento político visando a um "verdadeiro estado de exceção" que faça frente à violência do poder do Estado Moderno e do Direito, pois este ao legitimar a violência do Estado sobre os homens, institui e legitima a ordem econômica, política e social vigente: a ordem Mestrando em Filosofia no curso de Mestrado Acadêmico em Filosofia (CMAF) da Universidade Estadual do Ceará (UECE). Brasileiro, residente em Fortaleza-CE. Email: 
do capital e do fascismo nele entranhado.

\title{
2 A Crítica benjaminiana da Gewalt
}

O termo alemão "Gewalt" traz um duplo significado, podendo ser interpretado tanto como o "poder" quanto como a "violência". Por esse motivo entendemos que não existe poder sem violência. Alguns tipos de violência são sancionados, legitimados e outros não.

Em Sobre a Crítica do Poder como Violência, texto escrito em 1921 no contexto da Europa após a Primeira Grande Guerra Mundial, Walter Benjamin busca elaborar uma crítica do uso da violência a partir dos seguintes questionamentos: em que medida o uso da violência é ético? É justo lançar mão da violência como meio para alcançar fins justos? Enfim, o que legitimaria o uso da violência?

Para responder a tais questionamentos o autor inicia um diálogo com algumas vertentes da Filosofia do Direito: o direito natural e o direito positivo. A primeira destas vertentes, segundo Benjamin, "não vê qualquer problema na aplicação de meios violentos para fins justos". Como afirma o autor:

\begin{abstract}
De acordo com essa concepção (que serviu de base ideológica ao terrorismo na Revolução Francesa), a violência é um produto da natureza, qualquer coisa como uma matéria-prima para cujo uso não há entraves, a não ser que se abuse da violência para fins injustos (...) A filosofia popular darwinista mostrou muitas vezes como é pequeno o passo que leva desse dogma da história natural àquele outro, ainda mais grosseiro, da filosofia do Direito, que pretende que toda violência adequada quase exclusivamente a fins naturais seria, por si só, legitimável. (BENJAMIN, 2013a, 60)
\end{abstract}

Como podemos notar, o direito natural traz em si uma justificativa inconsistente para o uso de meios violentos. Nele, a violência, como um meio, é plenamente justificável, caso os fins sejam "legítimos" ou "naturais". Apoiada na concepção filosófica do jusnaturalismo, segundo a qual o homem sai do seu estado de natureza através de um contrato social, que atribui todo o poder ao soberano, o direito natural vê o direito como sendo natural e imutável.

Insatisfeito com a explicação do uso da violência dada pelo direito natural, Benjamin se aproxima do direito positivo enquanto este "vê o poder como dado historicamente adquirido" (BENJAMIN, 2013, 60). Não obstante reconheça que "as duas escolas encontram-se num dogma fundamental comum" que considera 
que "os fins justos podem ser alcançados por meios legítimos, e os meios legítimos, aplicados para alcançar fins justos" (BENJAMIN, 2013, 61-62), Benjamin encontra no direito positivo um fundamento hipotético aceitável para a investigação a qual se propõe, uma vez que este "estabelece uma distinção básica (...) entre a violência historicamente reconhecida, ou sancionada, e a não sancionada" (BENJAMIN, 2013, 61).

Assim, o direito positivo possibilita um ponto de vista acerca da violência do poder que revela o seu caráter histórico e, portanto, não-natural. O que existe, de fato, são tipos de violência que são sancionados, aprovados e outros que não são sancionados e, portanto, passíveis de punição; e isso não é naturalmente dado, mas histórico e socialmente construído.

Analisando a situação política da Europa de seu tempo, Benjamin encontra uma tendência do aparelho jurídico do Direito a perceber "o poder nas mãos de pessoas individuais como um perigo de subversão da ordem estabelecida".

O reconhecimento de um aspecto do poder como violência que escapa ao Direito, e que, portanto, estaria fora dele, é o fator que levará Walter Benjamin e Carl Schmitt a debaterem, como veremos adiante, acerca do "estado de exceção". A figura do "grande criminoso" e a concessão do direito à greve mostram como o Direito, na verdade, serve como fundador e mantenedor do status quo, legitimando todos os tipos de violência do Estado sobre os indivíduos, como é o caso paradoxal da pena de morte, exemplo-limite do poder do Estado sobre a vida dos indivíduos.

Mas é no que se refere à greve proletária, que Benjamin concentra sua análise. Embora o direito à greve dificilmente possa ser visto como uma violência, e talvez por isso ele tenha sido concedido ao proletariado, "o operariado organizado é, hoje em dia, o único sujeito jurídico, além do Estado, ao qual se concede a violência". Apoiado no texto Réflexions sur la Violence, de Georges Sorel, Benjamin distingue a greve geral política e a greve geral proletária. Enquanto a primeira visa manter e intensificar as relações jurídicas vigentes, a segunda tem o poder de instaurar novas relações jurídicas ${ }^{1}$.

1 Acerca da diferença entre os dois tipos de greve, Benjamin cita Sorel: "A greve geral política [...] demonstra como o Estado nada perderá da sua força, como o poder dos privilegiados passará para os privilegiados, como a massa dos produtores mudará de donos". Já a greve geral proletária "Elimina todas as consequências ideológicas de qualquer política social, seja ela qual Mestrando em Filosofia no curso de Mestrado Acadêmico em Filosofia (CMAF) da Universidade Estadual do Ceará (UECE). Brasileiro, residente em Fortaleza-CE. Email: 
É essa "função da violência", isto é, aquela que é capaz de instaurar novas relações jurídicas que Benjamin traz para o cerne do debate:

$\mathrm{Na}$ verdade, o que o Estado mais teme na greve é aquela função da violência que esta análise pretende investigar como único fundamento seguro da sua crítica. Se a violência fosse, como parece ser, apenas o meio de se apoderar imediatamente do que quer que seja que se pretende num dado momento, só poderia alcançar os seus fins sob a forma da violência de um assalto. O poder da violência seria, nesse caso, completamente inapto para instaurar ou modificar relações de forma relativamente estável. O exemplo da greve, porém, mostra que ela é capaz disso, que tem condições de instaurar e modificar relações jurídicas (...)

É no âmbito de uma Filosofia da História que Walter Benjamin encontra o ponto de vista, sob o qual, toda essa discussão acerca da violência ganha inteligibilidade, no contexto de sua produção conceitual. É no materialismo histórico e na sua teoria da "luta de classes" que o Direito aparece como instituidor e mantenedor dos privilégios das classes dominantes, como, por exemplo, ao justificar a propriedade privada.

Nesse contexto, a noção benjaminiana de "estado de exceção" parece emergir nesse debate com os juristas públicos de sua época, mais especificamente, como ressaltamos anteriormente, com Carl Schmitt, o jurista do Terceiro Reich alemão?2.

Veremos, a seguir, como a noção de estado de exceção é objeto de debate entre os dois pensadores alemães, para podermos então compreender como tal

for; os seus partidários veem todas as reformas, mesmo as mais populares, como burguesas. Esta greve geral anuncia claramente a sua indiferença em relação ao ganho material da conquista, ao declarar que quer acabar com o Estado; o Estado era realmente [...] a razão de ser dos grupos dominantes que tiram proveito de todos os empreendimentos cujo ônus recai sobre a generalidade da população" (SOREL apud Benjamin, 2013, 72)

2 A respeito da experiência do Terceiro Reich como laboratório de aperfeiçoamento do estado de exceção, Giorgio Agamben afirma: "Logo que tomou o poder (ou, como talvez se devesse dizer de modo mais exato, mal o poder lhe foi entregue), Hitler promulgou no dia 28 de fevereiro, O Decreto para a proteção do Povo e do Estado, que suspendia os artigos da Constituição de Weimar relativos às liberdades individuais. $O$ decreto nunca foi revogado, de modo que todo 0 Terceiro Reich pode ser considerado, do ponto de vista jurídico, como um estado de exceção que durou doze anos. O totalitarismo moderno pode ser definido, nesse sentido, como a instauração, por meio do estado de exceção, de uma guerra civil legal que permite a eliminação física não só dos adversários políticos, mas também de categorias inteiras de cidadãos que, por qualquer razão, pareçam não integráveis ao sistema político. Desde então, a criação voluntária de um estado de emergência permanente ( ainda que não declarado no sentido técnico) tornouse uma das práticas essenciais dos Estados contemporâneos, inclusive dos chamados demodráticos" (AGAMBEN, 2004, 12-13).

Mestrando em Filosofia no curso de Mestrado Acadêmico em Filosofia (CMAF) da Universidade Estadual do Ceará (UECE). Brasileiro, residente em Fortaleza-CE. Email: 
conceito aparece no pensamento benjaminiano em suas Teses sobre o Conceito de História, texto escrito por Benjamin em 1940, pouco tempo antes da sua morte.

\title{
3 O Estado de Exceção no debate Benjamin-Schmitt
}

Giorgio Agamben (2004), retoma de maneira bastante detalhada o "dossiê" da discussão entre Walter Benjamin e Carl Schmitt sobre o estado de exceção. Para o filósofo italiano, a gênese desse debate teria início não na leitura benjaminiana da Politische Theologie, mas na leitura de Schmitt do ensaio de Benjamin sobre a crítica da violência.

Conforme argumenta Agamben em Luta de gigantes acerca de um vazio, o jurista do Estado nazista teria desenvolvido a sua teoria da soberania "como resposta à crítica benjaminiana da violência" (AGAMBEN, 2004, 84). Segundo o autor, Benjamin utiliza, em seu ensaio de 1921, termos técnicos retirados do léxico schmittiano, como é o caso de "decisão" (Entscheidung), o que aponta para um debate direto entre os dois autores ${ }^{3}$.

Ao afirmar "a peculiar e desmoralizante experiência da indecidibilidade última de todos os problemas jurídicos" (BENJAMIN apud AGAMBEN, 2004, 85), Walter Benjamin estaria fazendo uma crítica direta à teoria schmittiana da "soberania", como estratégia para assegurar a existência de uma violência "pura" e "revolucionária" e, portanto, não circunscrita ao âmbito jurídico. Esclarecendo a estratégia benjaminiana Agamben afirma:

\begin{abstract}
O objetivo do ensaio é garantir a possibilidade de uma violência [...] absolutamente "fora" (ausserhalb) e "além" (jenseits) do direito e que, como tal poderia quebrar a dialética entre violência que funda o direito e a violência que o conserva [...] Benjamin chama essa outra violência de "pura" (reine Gewalt) ou de "divina" e, na esfera humana, de "revolucionária". O que o direito não pode tolerar de modo algum, o que sente como uma ameaça contra a qual é impossível transigir, é a existência de uma violência fora do direito [...] A tarefa da crítica benjaminiana é provar a realidade (Bestand) de tal violência (AGAMBEN, 2004, 84).
\end{abstract}

Desse modo, a tese schmittiana, segundo a qual o soberano é aquele que

3Publicado em 1921 no no 47 da Archiv für Sozialwissenschaften und Sozialpolitik, o ensaio Zur Kritik der Gewalt, teria sido lido por Carl Schmitt que àquela época era um leitor e colaborador assíduo da referida revista. Considerando essas informações, Agamben afirma "Schmitt dificilmente deixaria de notar um texto como "Crítica da Violência" que abordava (...) questões para ele essenciais" (AGAMBEN, 2004, 84).

Mestrando em Filosofia no curso de Mestrado Acadêmico em Filosofia (CMAF) da Universidade Estadual do Ceará (UECE). Brasileiro, residente em Fortaleza-CE. Email: 
decide em estado de exceção, ou seja, pela suspensão da norma que visa a manutenção da própria ordem, diante de insurreições e anomias, é uma resposta direta às formulações benjaminianas acerca da violência "revolucionária". Ainda conforme Agamben:

\begin{abstract}
A doutrina da soberania que Schmitt desenvolve em sua obra Politische Theologie pode ser lida como uma resposta precisa ao ensaio benjaminiano. Enquanto a estratégia da "Crítica da violência" visava assegurar a existência de uma violência pura e anômica, para Schmitt trata-se, ao contrário, de trazer tal violência para um contexto jurídico. O estado de exceção é o espaço em que ele procura capturar a ideia benjaminiana de uma violência pura e inscrever a anomia no corpo mesmo do nomos. [...] O estado de exceção é, pois, o dispositivo por meio do qual Schmitt responde à afirmação benjaminiana de uma ação humana inteiramente anômica (AGAMBEN, 2003, 85-85).
\end{abstract}

Ora, ao acompanharmos o desenrolar desse debate entre Benjamin e Schmitt acerca do estado de exceção, alcançamos o ponto no qual a oitava tese sobre o conceito de história ganha sua inteligibilidade. No contexto históricosocial da Alemanha nazista, Benjamin busca articular concepções teóricas que funcionem como "armas" contra o fascismo.

Bebendo da fonte marxiana do materialismo histórico e atribuindo ao historiador a tarefa de "escovar a história a contrapelo" e desembaraçar do esquecimento os ensinamentos que podemos aprender com os "vencidos" da história, Benjamin afirma:

\begin{abstract}
A tradição dos oprimidos ensina-nos que o "estado de exceção" em que vivemos é a regra. Temos de chegar a um conceito de história que corresponda a essa ideia. Só então se perfilará diante dos nossos olhos, como nossa tarefa, a necessidade de provocar o verdadeiro estado de exceção; e assim a nossa posição na luta contra o fascismo melhorará. (BENJAMIN, 2013b,13)
\end{abstract}

Dessa maneira, entendemos que "o verdadeiro estado de exceção" corresponde àquela violência "pura" e "revolucionária" do ensaio de 1921. Vemos assim que esse debate ocupou boa parte do pensamento político de Benjamin, preocupado que estava com a ascensão do fascismo.

\title{
CONCLUSÃO
}

O estado de exceção como regra e paradigma de governabilidade é hoje, de fato, uma realidade incontestável. Cada vez mais o Direito parece ser o âmbito em que muitos aspectos da vida política contemporânea se decidem. É Mestrando em Filosofia no curso de Mestrado Acadêmico em Filosofia (CMAF) da Universidade Estadual do Ceará (UECE). Brasileiro, residente em Fortaleza-CE. Email: 
por meio do entrecruzamento entre o Direito e outros dispositivos biopolíticos que a vida da população é gerida e os crimes de Estado cometidos em nome da manutenção e ampliação do capitalismo são "legitimados" e passam a fazer parte do modus operandi dos Estados contemporâneos.

No entanto, são inúmeras as experiências de resistência da população diante desse uso da violência institucional, seja através de práticas diretas como ocupações de espaços públicos por organizações populares não hierarquizadas, seja através da arte e dos encontros entre pessoas. Assim, podemos perceber que a "violência pura" e "revolucionária" a qual se referia Benjamin ainda vive, intempestiva, pronta a destruir o poder do Estado e produzir o "verdadeiro estado de exceção".

\section{REFERÊNCIAS}

AGAMBEN, Giorgio. Estado de Exceção. Trad. Iraci D. Poleti. 2ed. Boitempo, São Paulo, 2004.

BENJAMIN, Walter. Sobre a crítica do poder como violência. In: Walter Benjamin: $O$ anjo da História. Trad. João Barrento. 2ed. Autêntica. Belo Horizonte, 2013a; p. 57-82.

"Crítica da violência - crítica do poder" in:_Documentos de cultura documentos de barbárie (Org e Apres. Willi Bolle), Tradução Willi Bolle, Celeste Ribeiro de Sousa et allii, São Paulo: Editora da Universidade de São Paulo, 1986, pp.160-175.

Sobre o Conceito da História. In: Walter Benjamin: $O$ anjo da História. Trad. João Barrento. 2ed. Autêntica. Belo Horizonte, 2013b; p. 7-20.

CALLADO, Tereza de Castro. "O Itinerário da moral e a lógica política do estado de exceção em Walter Benjamin" acessível no site: www.filosofia.fflch.usp.br/teses/filosofia/2005

"A lógica da exceção na reflexão política de Walter Benjamin" in:__Subjetividade e Educação, Fortaleza: Edições UFC, 2012

SOREL, George, Reflexões sobre a violência. Tradução de Orlando dos Reis, Petrópolis: Vozes, 1993.

Réflexions sur la violence, 5 Éditions, Paris, 1919. 